\title{
El Partido Nacional uruguayo ante las elecciones de 1930
}

\author{
Carolina Cerrano* \\ José Saravia**
}

Fecha de Recepción: 15 de junio de 2021

Fecha de Aceptación: 17 de agosto de 2021

DOI: https://doi.org/10.46553/RGES.57.2021.p.258-280

\begin{abstract}
Resumen
Este artículo investiga la campaña electoral de 1930 del Partido Nacional uruguayo a través de su prensa partidaria. En el trabajo se analizan los ejes temáticos de la agenda electoral, las ideas claves, propuestas y principales líneas de su discurso político en relación con temas como la inmigración, la reforma constitucional y la crisis económica, entre otros. Asimismo, se examinan las discusiones que se produjeron dentro de filas para procesar el adverso resultado comicial. La derrota ante su tradicional adversario colorado, por una mayor amplitud en el número de sufragios en comparación con las elecciones precedentes, profundizó las diferencias internas. De tal modo, se demuestra cómo en diciembre de 1930 comienzan a percibirse cada vez mayores rispideces y fricciones entre los sectores del nacionalismo, en las que la figura de Luis Alberto de Herrera tuvo un peso central, marcando el inicio de una ruptura que se ahondaría en los meses siguientes, y que contrastaba con la unidad pregonada a lo largo de la década de 1920.
\end{abstract}

Palabras clave: Partido Nacional; Uruguay; elecciones de 1930; Luis Alberto de Herrera

\begin{abstract}
This article investigates the 1930 electoral campaign of the Uruguayan National Party through its partisan press. The work analyzes the thematic axes of the electoral agenda, the key ideas, proposals, and main lines of its political discourse in relation to issues such as immigration, constitutional reform, and the economic crisis, among others. Also are examined the discussions that occurred inside the party to process the adverse electoral result. The defeat against its traditional Colorado adversary, due to a greater number of votes compared to the previous elections, deepened the internal differences. It is shown how in December 1930 began to be perceived between the sectors of nationalism greater risks and frictions, in which the figure of Luis Alberto de Herrera had a central significance, marking the beginning of a rupture that would deepen in the months that followed, and in contrast to the unity touted throughout the 1920 s.
\end{abstract}

Keywords: National Party; Uruguay; 1930 elections; Luis Alberto de Herrera

\section{Introducción}

Este artículo estudia la campaña política del Partido Nacional uruguayo en las elecciones de 1930 desde su prensa partidaria. Luis Alberto de Herrera y Eduardo Lamas fueron los dos candidatos presidenciales del nacionalismo. Al final, el Partido Nacional,

\footnotetext{
Universidad de Montevideo - Agencia Nacional de Investigación e Innovación, Uruguay, Montevideo, ccerrano@um.edu.uy

${ }^{* *}$ Universidad Rusa de Amistad de los Pueblos, Rusia, Moscú, joseasaravia@outlook.com
} 
después de más de sesenta años de espera, otra vez perdió la elección frente a su histórico rival, el Partido Colorado. Está investigación se inscribe en un proyecto de mayor envergadura sobre las campañas electorales en las que participó Luis Alberto de Herrera entre 1922 y 1958. ${ }^{1}$ La figura de este líder, alrededor del cual gravitó la política nacionalista en el periodo mencionado, no se ha trabajado en profundidad, a diferencia del interés que ha suscitado el abordaje del Herrera historiador y el análisis de su pensamiento políticointelectual. $^{2}$

El 30 de noviembre de 1930 las elecciones uruguayas concitaron atención regional. Las rupturas institucionales de Bolivia, Perú, Argentina y Brasil de ese año marcaron la jornada comicial, en un escenario en que los regímenes y movimientos totalitarios europeos ponían en cuestionamiento la democracia. Uruguay, que se vanagloriaba de la madurez en su conquista de la libertad política, no era ajeno a ese contexto que, además, incluía una crisis económica a escala global. En esta dinámica, esas elecciones serían visualizadas por el Partido Nacional como una necesidad histórica de concretar la rotación de los partidos en el poder como símbolo de la coronación republicana del país.

Asimismo, estas elecciones han cobrado un peso significativo en la historia uruguaya a raíz de los acontecimientos que se precipitarían después de ellas. El nacionalismo ahondó de forma irremediable sus diferencias, lo que se plasmaría en el nacimiento del Partido Nacionalista Independiente, abanderado del antiherrerismo. En ello pesaron las discrepancias internas sobre la conducción y reorganización partidaria tras la derrota, y cómo se fueron trenzando los vínculos con el nuevo gobierno colorado en un marco en el que la crisis mundial impactaba con fuerza en la economía, política y sociedad uruguaya. Los acontecimientos tomaron un rumbo dramático el 31 de marzo de 1933 con el golpe de Estado protagonizado por el presidente Gabriel Terra, que contó con el apoyo del herrerismo. Los derroteros de esta historia escapan a este artículo, pero ponen en perspectiva la importancia de

\footnotetext{
${ }^{1}$ Carolina Cerrano y José Saravia. "La primera elección presidencial de Luis Alberto de Herrera desde el discurso del candidato y la prensa partidaria (1922)", Prohistoria. Historia, políticas de la Historia, $\mathrm{n}^{\circ} 35$ (2021): 47-68. [https://ojs.rosario-conicet.gov.ar/index.php/prohistoria/article/view/1404] y Carolina Cerrano y José Saravia. "El discurso del Partido Nacional uruguayo en las elecciones de 1925 y 1926", Revista Historia (aceptado para publicar), 2022.

${ }^{2}$ Sobre la trayectoria política e intelectual de Herrera en las tres primeras décadas del siglo XX, el libro más completo es: Laura Reali. Herrera. La revolución del orden: Discursos y prácticas política, 1897-1929. (Montevideo: Ediciones de la Banda Oriental, 2016). Dos libros clásicos sobre su pensamiento políticointelectual son los siguientes: Carlos Real de Azúa. Herrera: la construcción de un caudillo y de un partido. (Montevideo: Cal y Canto, 1994) y Carlos Zubillaga. Herrera: la encrucijada nacionalista. (Montevideo: Arca, 1976). Gerardo Caetano en un reciente libro dedica un capítulo a Luis Alberto de Herrera, sin ahondar en profundidad en su trayectoria política posterior a la década del treinta: Gerardo Caetano. El liberalismo conservador. (Montevideo: Ediciones de la Banda Oriental, 2021), 151-179.
} 
analizar con mayor exhaustividad histórica las últimas elecciones presidenciales antes de la primera ruptura institucional del siglo XX uruguayo.

En relación con las fuentes primarias de este artículo, los medios periodísticos manejados son El País, La Tribuna Popular, Diario del Plata y El Nacional, editados en Montevideo y con alcance nacional. Todos ellos, con sus singularidades, se identificaban con el Partido Nacional. ${ }^{3}$ Al igual que en otras campañas políticas de la década del veinte, el peso de la propaganda se centraba en el partido y no en las individualidades de sus candidatos. No obstante, en cada medio son patentes sus proximidades ideológicas con las distintas tendencias partidarias. La Tribuna Popular se definía como la voz de los sectores populares y acompañaba fervientemente a Herrera y sus acólitos. En El País participaban miembros del directorio del partido y políticos de dilatada trayectoria, que mostraron su preferencia por Lamas, y durante los últimos diez años crecía su preocupación por el crecimiento del liderazgo herrerista. Diario del Plata era una empresa a cargo de Juan Andrés Ramírez, un político nacionalista que discrepaba abiertamente del personalismo herrerista y al mismo tiempo manifestaba cierta independencia con los núcleos más conservadores. Por su parte, $E l$ Nacional, nacido a mediados de 1930, era la voz del grupo de Carlos Quijano, que no mostró preferencias respecto a las candidaturas, porque ninguna de las dos presentaba una renovación ideológica como la que ellos esperaban dentro del partido. Las fuentes consultadas se han complementado con el relevamiento de la correspondencia recibida por Luis Alberto de Herrera en 1930 con el objetivo de reconstruir las percepciones del público nacionalista por su candidatura.

En relación con la metodología, esta investigación utiliza de forma amplia las herramientas teóricas provistas por el análisis del discurso y otros autores que han profundizado en sus estudios el valor de las palabras y cómo a través del lenguaje verbal se interpreta una determinada realidad social. Con este proceder metodológico se pretende, como paso previo a la interpretación historiográfica, evitar las transferencias de cargas semánticas del presente al pasado y situar al pasado en su propio lenguaje, lo que se logra mediante la detección de los recursos lingüísticos de determinada época, teniendo en cuenta su contexto social y económico. En particular, se analizan las variantes con las que el Partido Nacional como comunidad política se expresaba a sí mismo a través de metáforas, para de este modo justificar su existencia, establecer cómo podían pertenecer a él los individuos y cómo

\footnotetext{
${ }^{3}$ Para más información sobre estos periódicos, véase: Daniel Álvarez Ferretjans. Desde la Estrella del Sur a Internet: Historia de la Prensa en el Uruguay. (Montevideo: Búsqueda-Fin de Siglo, 2008), 208-209, 232, 339340, 442, 446, 461-464, 488.
} 
articulaba y definía la unidad y la pluralidad tanto dentro del partido como en relación con los otros grupos del espectro político. ${ }^{4}$

\section{Los partidos tradicionales uruguayos y el funcionamiento electoral}

En 1917 Uruguay había reformado su constitución: entre las novedades se instaló un poder ejecutivo bicéfalo, es decir, al presidente lo acompañaba un Consejo Nacional de Administración [CNA, en adelante], que se hacía cargo de economía, finanzas, obras públicas, justicia e instrucción pública. Desde entonces, las elecciones se desarrollaron de forma regular cada dos años para la renovación del CNA y cada cuatro las presidenciales. La naciente democracia uruguaya, que también plasmó en esta constitución el voto secreto y la representación proporcional, se estaba afianzando, a pesar de que las denuncias de fraude entre ambos partidos tradicionales seguían siendo una constante en los comicios. El Partido Nacional, principal partido de la oposición, gradualmente acortaba distancias con el oficialista Partido Colorado: ya disponía de una mayoría en el Senado, una representación significativa en Diputados y varias jefaturas departamentales, pese a que todavía era minoría en el CNA y no lograba hacerse con la primera magistratura.

De la legislación electoral uruguaya es preciso consignar que la votación no era obligatoria, aunque los datos de la década del veinte indicaban que la participación popular estaba aumentando, lo que era interpretado por los contemporáneos como un reflejo de una mayor confianza en el sistema. Por añadidura, regía una "ley de lemas", por medio de la cual en una campaña electoral un partido podía presentar diferentes candidatos y sumar así votos al lema común. En 1922 y en 1926 el candidato nacionalista Luis Alberto de Herrera había obtenido individualmente más votos que los electos presidentes colorados, José Serrato y Juan Campisteguy, quienes se habían beneficiado de las ventajas legales de sumar los sufragios de las distintas fracciones de su partido.

En cuanto al Partido Colorado, cabe mencionar que su principal referente, José Batlle y Ordóñez, líder de la tendencia mayoritaria denominada "batllista", había fallecido en 1929. Su figura había dividido a las filas, pero al mismo tiempo era el estratega de las alianzas electorales que le habían permitido conservar el poder, por más que ello le implicó arrinconar

\footnotetext{
${ }^{4}$ Véase Teun A. van Dijk. El análisis crítico del discurso. Barcelona: Anthropos, 1999; Quentin Skinner, "Significado y comprensión en la historia de las ideas", Prismas: revista de historia intelectual n 4 (2000): 149194; John Pocock. Pensamiento político e historia. (Madrid: Akal, 2011); Reinhart Koselleck. Futuro pasado: Para una semántica de los tiempos históricos. (Barcelona: Paidós, 1993); y George Lakoff y Mark Johnson. Metáforas de la vida cotidiana. (Madrid: Cátedra, 1991).
} 
proyectos políticos progresistas más ambiciosos. El batllismo había plasmado un conjunto de reformas económicas, sociales y culturales que marcaron al Uruguay de las primeras tres décadas del siglo. Como representante de la izquierda del partido era un genuino defensor de que el Estado asumiera roles más activos de intervención económico-social, y otra de sus banderas era el anticlericalismo. Asimismo, los colorados tenían un ala conservadora, el riverismo, que había nacido bajo el influjo de la personalidad de Pedro Manini Ríos y nucleaba las preferencias de algunas clases propietarias y conservadoras, ya que eran un dique de contención a las iniciativas batllistas. De hecho, en varias oportunidades nacionalistas y riveristas habían votado juntos en el parlamento y en el CNA. También entre los colorados había neutrales y otros grupos que respondían a sus mentores políticos. ${ }^{5}$

En 1930 el nacionalismo llevaba más de sesenta años anhelando la presidencia, deseo incrementado porque cuatro años antes había perdido por una mínima diferencia de 1.500 votos frente a su habitual rival. ${ }^{6}$ La derrota del 28 de noviembre de 1926 tendría un enorme peso en la historia partidaria posterior, considerando que fue la oportunidad más cercana a la esperada victoria del poder ejecutivo que solo se haría realidad en 1958. El peso de ese pasado reciente estaría presente en la campaña electoral que se analiza en este artículo. El Partido Nacional gozaba de una mayor cohesión partidaria que su adversario tradicional, sin embargo, esto no niega la existencia de rivalidades internas que iban desde distintos estilos de conducción a diferentes criterios ideológicos ante lo que se percibía como nuevos tiempos. Hacia 1928 nació dentro del partido un ala hacia la izquierda, la Agrupación Nacionalista Demócrata Social, dirigida por Carlos Quijano. ${ }^{7}$ Asimismo, en 1930, entraron en escena los hijos del legendario caudillo Aparicio Saravia, quienes se oponían al colegiado y amenazaban con una revolución para modificar la constitución. ${ }^{8}$

\footnotetext{
5 Para ampliar sobre el batllismo se recomienda: Gerardo Caetano. La República Batllista. (Montevideo: Ediciones de la Banda Oriental, 2015). En el siguiente libro que se cita Caetano aborda cómo las clases conservadoras reaccionaron frente al batllismo: Gerardo Caetano. La República Conservadora (1916-1929): Tomo II: La “Guerra de Posiciones". (Montevideo: Fin de siglo, 1993).

${ }^{6}$ En cuanto a la campaña electoral nacionalista de 1926 y sus disputas legales tras los comicios, véase: Göran Lindahl. Batlle: Fundador de la democracia en el Uruguay. (Montevideo: Arca, 1971), 176-210; Gerardo Caetano, La República Conservadora, 131, 143-171; Carlos Manini Ríos. La Cerrillada. (Montevideo: Imprenta Letras, 1973); Washington Reyes Abadie. Breve historia del Partido Nacional. (Montevideo: Ediciones de la Banda Oriental, 1989), 200-207; Milton I. Vanger. José Batlle y Ordóñez: La elección de 1926. (Montevideo: Ediciones de la Banda Oriental, 2012).

7 Gerardo Caetano y José Rilla. El joven Quijano, 1930-1933: izquierda nacional y conciencia crítica. (Montevideo: Ediciones de la Banda Oriental, 1986), 66-70.

${ }^{8}$ Gerardo Caetano y Raúl Jacob, El nacimiento del terrismo (1930-1933), Tomo. 1. (Montevideo: Ediciones de la Banda Oriental, 1989), 161. Es oportuno consignar que los neosaravistas no congregaron atención de la prensa nacionalista en los meses de noviembre y diciembre de 1930.
} 
Por otra parte, el nacionalismo ya había sufrido escisiones, especialmente por razones ideológicas. En 1926 el radicalismo blanco, un grupo expulsado por el directorio del partido, votó fuera del lema obteniendo 3.844 votos, los que podrían haber sido decisivos para una victoria nacionalista. En 1930 la dirigencia del Partido Nacional hizo infructuosos intentos por lograr su "solidaridad" y su retorno a la "gran familia nacionalista". No obstante, los líderes radicales rechazaron volver al seno del partido y proclamaron la abstención electoral. ${ }^{9}$

En las presidenciales de 1930 el Partido Nacional presentó como candidatos a Luis Alberto de Herrera y a Eduardo Lamas, cuyos votos se sumarían al lema común. ${ }^{10}$ Durante la década del veinte Herrera venía consolidando su peso político dentro del partido. A pesar de sus derrotas en 1922 y 1926, afianzó su prestigio como líder gracias al incremento de su caudal electoral y la confianza de algunos dirigentes. Sin embargo, a la par se acrecentaron los cuestionamientos por parte de sus detractores, que expresaban los peligros de la aparición del personalismo y la demagogia, concebidos como la antítesis de la democracia. De hecho, su sector ya se definía abiertamente como herrerista en 1930, lo que antes se insinuaba de forma tímida y esporádica. La candidatura de Eduardo Lamas, hijo de un prócer partidario, se identificaba con la rama más conservadora del partido y reunía seguidores entre los opositores de Herrera.

A pesar de la esperanza nacionalista, el Partido Colorado ganó las elecciones y Gabriel Terra llegó a la primera magistratura. El lema colorado obtuvo 167.827 sufragios (52\%) y el Partido Nacional 150.642 (47\%), con una diferencia de 15.185 votos. ${ }^{11}$ Si bien la diferencia fue nuevamente escasa, en verdad la brecha que separaba a ambos partidos creció si se considera la elección presidencial previa de 1926, que fue de solo 1.500 votos. El análisis de las causas de la derrota derivó en varias discusiones, iniciadas inmediatamente de conocerse

\footnotetext{
${ }^{9}$ El libro más completo sobre los blancos radicales es: Carlos Zubillaga. Las disidencias del tradicionalismo: El radicalismo blanco. (Montevideo: Arca-CLAEH, 1979), 64-66.

${ }^{10}$ También se renovaban cargos para el CNA, que estaba compuesto por nueve miembros. En 1930 cuatro eran nacionalistas y cinco colorados. El $1^{\circ}$ de marzo de 1931 abandonarían su puesto dos nacionalistas y un colorado, es decir, aunque el Partido Nacional obtuviera la mayoría en la elección solo podría aspirar a mantener sus cuatro consejeros y continuaría en minoría en ese organismo.

11 Julio Fabregat. Elecciones uruguayas (febrero de 1925 a noviembre de 1946). (Montevideo: Cámara de Representantes, 1950), 133-134. En estas elecciones el comunismo obtuvo 2.291 sufragios. La prensa nacionalista no le prestó atención a su campaña política y a su minúsculo desempeño electoral. En cuanto a los cargos que se renovaban en el CNA las diferencias con la elección presidencial fueron mínimas: el Partido Colorado obtuvo 165.828 votos, el Partido Nacional 149.978 y el Partido Comunista 2.258.
} 
el resultado electoral y que se profundizarían a lo largo del año siguiente, sellando la "rápida fractura dentro del nacionalismo". ${ }^{12}$

\section{El discurso electoral del Partido Nacional}

En vísperas de los comicios el nacionalismo repetía su constante avance electoral, el augurio "definitivo" de la rotación de partidos y su confianza en la victoria, que se daría contra todas las fuerzas coloradas, ya estuvieran juntas o separadas. ${ }^{13}$ En paralelo, otro leitmotiv de campaña era el contraste entre su unidad y armonía, organización superior y conciencia de responsabilidad frente al "pandemónium colorado", visualizado en su peor momento histórico debido a la defunción de José Batlle y Ordóñez el año anterior. ${ }^{14}$ El Partido Colorado era presentado como anómalo por la convivencia en su interior de los extremos políticos: desde los "bolcheviques" (batllistas) hasta los "ultraconservadores o aristócratas" (riveristas), solo unidos para perpetuarse en el poder. ${ }^{15}$ Por su parte, el nacionalismo se concebía como una fuerza política ajena a los extremismos y con una "orientación definida". ${ }^{16}$ Para El Nacional, en la elección se jugaba la "estabilidad democrática” del país que solo podía ser garantizada por el Partido Nacional. Este, a pesar de “divergencias ideológicas” en materia económica y social, mantenía una cohesión que respondía a los sagrados ideales de la libertad política. ${ }^{17}$ En un año cargado de simbolismo en Uruguay por la celebración del centenario de su primera constitución, el Partido Nacional hacía gala de su identidad democrática y de sus aportes a la construcción de la libertad política a lo largo de ese siglo, en la que aportaron derechos fundamentales, como el voto

\footnotetext{
${ }^{12}$ Caetano y Jacob, El nacimiento del terrismo, (Montevideo: Ediciones de la Banda Oriental, 1989), 188, 163170. Este libro es el trabajo más completo en el análisis del año electoral de 1930 hasta el golpe de Estado de 1933.

13 "El Partido Nacional y la unificación colorada", Diario del Plata, 1 de noviembre, 1930, 3; "La rotación de los partidos", El Nacional, 26 de noviembre, 1930, 1; "En el campo electoral: Como avanza el nacionalismo", Diario del Plata, 12 de noviembre, 1930, 3.

14 "La cohesión nacionalista y el pandemónium colorado", Diario del Plata, 2 de noviembre, 1930, 3; "La situación de los partidos en los momentos decisivos”, El País, 6 de noviembre, 1930, 5; “Hay un Partido Colorado?", El País, 5 de noviembre, 1930, 5; “Con unificación o sin unificación”, El País, 3 de noviembre, 1930, 5; "La opción es clara", El Nacional, 26 de noviembre, 1930, 1.

15 "La farsa del coloradismo", El País, 9 de noviembre, 1930, 5; "Nosotros y ellos", El País, 2 de noviembre, $1930,5$.

16 “El Partido Nacional está de pie: un hermoso espectáculo”, El País, 11 de noviembre, 1930, 5; “Aspectos de la lucha: intervención en Montevideo", El País, 11 de noviembre, 1930, 5. Desde El País se denunciaba a los colorados que escribían sobre la falta de unidad nacionalista: “QQué frescos!”, El País, 11 de noviembre, $1930,5$.

17 "Hoy y aquí", El Nacional, 8 de noviembre, 1930, 1; "Frente a los comicios: lo que nos une", El Nacional, 22 de noviembre, 1930, 1; "El tradicionalismo", El Nacional, 23 de noviembre, 1930, 1. El País también destacaba la ausencia de extremismos dentro del partido: "La unión del Partido Nacional", El País, 15 de noviembre, 1930, 5 .
} 
secreto y la representación proporcional, frente a los atropellos del fraude y las persecuciones oficialistas.

En relación con lo anterior, desde la visión de los nacionalistas, el Partido Colorado de forma incesante vilipendiaba los logros democráticos alcanzados. Cada campaña política era ocasión de presentar las antinomias que los separaban de sus adversarios tradicionales, pero en esta elección un tema puso la voz de alarma: la "fórmula bicloruro" o hándicap. Un acuerdo colorado, escasas semanas antes del 30 de noviembre, por medio del cual si Pedro Manini Ríos obtenía el $17.5 \%$ de los sufragios o más -representados en unos veinte cinco o veinte seis mil- Gabriel Terra, que probablemente sería el más votado, se comprometía a renunciar a la presidencia y se la transferiría a Manini Ríos. El directorio del Partido Nacional se pronunció en contra de que el oficialismo resolviera un "pleito interno" violando las leyes democráticas y constitucionales, sintetizadas en el respeto del mandato de las mayorías. Además, se remarcó que el Partido Nacional era mayoría en el Senado y que, si Manini Ríos fuera el presidenciable, no sería copartícipe de un pacto ilegal e inmoral.

En inconmensurables artículos la prensa nacionalista se hizo eco del rechazo del hándicap entre la ciudadanía de distintos colores políticos, incluso de los batllistas, y se celebró que algunos colorados se pasaran a las filas nacionalistas frente a este atentado a la dignidad y a la moral republicana. ${ }^{18}$ La Tribuna Popular defendió la abstención como una necesidad, un derecho y una forma de protesta para los ciudadanos colorados "que aman la paz, el orden y la Patria" frente al "manoseo" y "engaño" de sus autoridades, ya que decidían por ellos el destino de su colectividad política sin consultarlos y así tergiversaban su voto. ${ }^{19}$ Como contrapartida, El Nacional tenía una visión de profunda condena hacia la abstención, puesto que era incompatible con el espíritu de la democracia. De tal modo, todos los ciudadanos tenían el "deber primordial y fundamental" de ejercer el sufragio. ${ }^{20}$ Basados en el sistema de leyes y garantías electorales, la existencia de "plena libertad política" y de

\footnotetext{
${ }^{18}$ Como ejemplos, véase: "El directorio del Partido se pronuncia contra el hándicap", El País, 4 de noviembre, 1930, 5; "La mayoría del senado repudia el expediente antidemocrático denominado hándicap", El País, 14 de noviembre, 1930, 5; "El hándicap: circular del directorio del Partido Nacional a las comisiones departamentales", El País, 18 de noviembre, 1930, 5; "Dos colorados radicales, se hacen nacionalistas", El País, 12 de noviembre, 1930, 5; "Más que nunca es necesario el triunfo nacionalista", El Nacional, 12 de noviembre, 1930, 1; "Rechazaron el hándicap", La Tribuna Popular, 14 de noviembre, 1930, 1.

19 “Manini obtendrá el 17.50!", La Tribuna Popular, 30 de noviembre, 1930, 1; "Los ciudadanos colorados no pueden dejarse manejar como muñecos", La Tribuna Popular, 2 de noviembre, 1930, 1; "No se deje engañar", La Tribuna Popular, 8 de noviembre, 1930, 1. Para este medio, la abstención era recomendable para los colorados, pero bajo ningún concepto englobaba los nacionalistas. De hecho, hay muchas notas que denuncian la indiferencia electoral como un crimen. "Hay que saber votar", La Tribuna Popular, 13 de noviembre, 1930, 1.

20 "No habrá abstenciones", El Nacional, 24 de noviembre, 1930, 1; "Independencia política no implica abstencionismo", El Nacional, 30 de noviembre, 1930, 1.
} 
múltiples listas en cada partido, que podían expresar las aspiraciones de cada votante, afirmaban que "No hay un solo motivo, uno solo que justifique la abstención". ${ }^{21}$ Incluso llegaron al punto de sostener que era preferible votar al Partido Colorado, antes de que la persona se abstuviera.

El discurso nacionalista ofrecía libertad, tolerancia, patriotismo, la unión de los uruguayos, justicia, una nueva etapa de progreso -moral y material-, civilización, cultura, honradez y austeridad administrativa, bienestar social y el perfeccionamiento de las instituciones democráticas. En ese "destino seguro" y "feliz" un gobierno nacionalista nunca sería sectario ni exclusivista. ${ }^{22}$ De tal modo, Lamas llevó la bandera artiguista de "Patria para todos" y Herrera prometió gobernar "con el país para el país". Este último reiteró conceptos vertidos en anteriores campañas, tales como que la democracia sería una verdad, una garantía de respeto a las leyes, a la constitución, a los adversarios y una obra constructiva para el trabajo y el capital. ${ }^{23}$ El Partido Nacional pregonaba que sería el único que daría tranquilidad y orden a la república, cada día más necesarios frente a las amenazas que se cernían en el mundo sobre las democracias. ${ }^{24}$ Leonel Aguirre, presidente del directorio nacionalista, presentó en un discurso a la lucha comicial como "coronamiento de la obra de muchas generaciones" con el objetivo de "divisar la tierra prometida" después de más de sesenta años. ${ }^{25}$ Esa "tierra prometida" era símbolo del bien, de la paz, de la verdad, de lo sano y de la luz que encarnaba el Partido Nacional para un "pueblo viajero" que se había extraviado por distintos senderos producto de los “malos guías". Para La Tribuna Popular, Herrera era el conductor popular que necesitaba ese pueblo. ${ }^{26}$ En consecuencia, para este medio, en un marcado lenguaje populista, el pueblo soberano debía optar entre su salvación o el abismo y los nacionalistas eran los “verdaderos demócratas", depositarios de las virtudes morales frente

\footnotetext{
21 "No es honesto ni licito abstenerse", El Nacional, 15 de noviembre, 1930, 1.

22 "Por medio de la radio, los candidatos nacionalistas dirigieron anoche la palabra al pueblo", Diario del Plata, 7 de noviembre, 1930, 3; "Todo induce a confiar en la victoria", El Nacional, 20 de noviembre, 1930, 1; "La concordia del partido lo afirma", El País, 27 de noviembre, 1930, 5; "Vote por Herrera, vote por Lamas", El País, 27 de noviembre, 1930, 5; "Lo que es y lo que quiere el Partido Nacional", El País, 27 de noviembre, 1930, 5; "El pueblo debe elegir: Herrera o Terra", La Tribuna Popular, 16 de noviembre, 1930, 1.

23 "Patria para todos: La palabra de los candidatos", Diario del Plata, 8 de noviembre, 1930, 3; "Con el país para el país", Diario del Plata, 16 de noviembre, 1930, 3; "Anoche el Dr. Luis A. de Herrera expuso al país su programa de gobierno", La Tribuna Popular, 7 de noviembre, 1930, 1.

24 "Los afiliados a los partidos menores", El Nacional, 30 de noviembre, 1930, 1.

25 "No existen proscriptos o excluidos en el Partido Nacional: fueron estas las palabras de Leonel Aguirre", $E l$ País, 13 de noviembre, 1930, 5 .

26 "Nuestra palabra ante el porvenir de la Nación", La Tribuna Popular, 6 de noviembre, 1930, 1. Durante todo noviembre se intercalaron en las páginas de este medio comentarios de diferentes correligionarios y ciudadanos representativos del comercio, la industria y de la campaña que afirmaban porqué debía elegírselo presidente.
} 
a los demagogos o "falsos demócratas", presentados como traficantes, mercaderes, corruptos, egoístas e inmorales, en concreto, unos "explotadores" y "enemigos" del pueblo. ${ }^{27}$

Como se ha señalado anteriormente, pese a que el nacionalismo manifestaba con orgullo su armonía partidaria, no todo era color de rosa en la pugna interna. Un tema que despertó un enconado debate fue la solicitud de un grupo de correligionarios de separar las listas de votación para presidente de las del CNA, lo que habilitaba a los ciudadanos a votar solo por candidato a presidente sin hacerlo por los consejeros, o viceversa. ${ }^{28}$ El Nacional señaló que la división de listas era una incoherencia peligrosa e implicaría agravar las desventajas del gobierno colegiado, en vista de que ganar el Consejo y perder la presidencia era una victoria a lo Pirro. ${ }^{29}$ La Tribuna Popular tuvo una lectura de alarma y la evaluó como una maniobra "turbia y anti-herrerista" que boicoteaba la llegada del candidato "popular" al puesto que le correspondía "por honor". Debido a esto alertaban que Herrera tenía "enemigos", movidos por el "odio, la "traición” y la "indisciplina” sembrando la "desunión y la discordia" nacionalista, explotada a favor del oficialismo. ${ }^{30}$ Finalmente, el directorio rechazó la propuesta. ${ }^{31}$

En el nacionalismo había impaciencia por alcanzar la victoria, y pavor de que se repitiese el drama de 1926. Aunque oficialmente el radicalismo proclamó la "decisión suicida" de la abstención, este recibió un trato amable por parte de la dirigencia y atención mediática. ${ }^{32}$ Por ejemplo, el directorio y la convención ofrecieron una "amplia" y "generosa" "amnistía" con el objetivo de "alzar los espíritus en un momento decisivo para la causa por la que se han hecho tantos sacrificios". ${ }^{33}$ De tal modo, se buscaba colocar por encima el objetivo común de derrotar al coloradismo, a pesar de las desavenencias que habían ocurrido en su

\footnotetext{
27 "Lo inconcebible", La Tribuna Popular, 13 de noviembre, 1930, 1; "Y esos son los demócratas", La Tribuna Popular, 15 de noviembre, 1930, 1; "El triunfo popular del día 30”, La Tribuna Popular, 17 de noviembre, 1930, 1.

28 "El Partido Nacional debe respetar la libertad de cada elector”, El Nacional, 2 de noviembre, 1930, 1. En este artículo se explica con más detalle el sentido de su propuesta.

29 "Como se plantea la elección”, El Nacional, 4 de noviembre, 1930, 1; "La cuestión de las listas", El Nacional, 4 de noviembre, 1930,1 .

30 "Una maniobra ramirizta contra el Dr. Herrera", La Tribuna Popular, 1 de noviembre, 1930, 1; "La maniobra contra el Dr. Herrera", La Tribuna Popular, 2 de noviembre, 1930, 1; "La hora angustiosa", La Tribuna Popular, 3 de noviembre, 1930, 1. Con argumentos similares, Diario del Plata sostuvo que quien votara a consejeros nacionalistas tenía que hacer lo mismo con la presidencia. "En rigor de lógica", Diario del Plata, 4 de noviembre, 1930, 3; "Hay que afrontar la lucha íntegramente", Diario del Plata, 5 de noviembre, 1930, 3; "El deber ante los comicios", Diario del Plata, 11 de noviembre, 1930, 3; "Ante los comicios", Diario del Plata, 21 de noviembre, 1930, 3.

31 "El gran triunfo popular es nuestro triunfo", La Tribuna Popular, 4 de noviembre, 1930, 1.

32 "Los blancos radicales en los comicios", El País, 28 de noviembre, 1930, 5.

33 "Por la concordia partidaria", El País, 5 de noviembre, 1930, 5; "La amnistía partidaria: solución de un problema interno", El País, 8 de noviembre, 1930, 5.
} 
pasado reciente. Si bien era un hecho favorable que los radicales blancos no presentarían candidatos, tampoco existía certeza sobre qué harían sus seguidores. En este sentido, se hacían públicas cartas en las que ciudadanos radicales blancos agradecían la amnistía decidida por la convención y sostenían que se volcarían en las urnas por el Partido Nacional para vencer al enemigo habitual o camarilla batllista. ${ }^{34}$ Otra forma de propaganda para atraer su voto fue mediante la publicación de eslóganes cortos, pero llenos de significado, que se centraban en resaltar la idea de unidad, la tradición y llamaban a votar "por nuestros muertos por los 50 años de esfuerzos desde la llanura en bien de la causa común". ${ }^{35}$ Por su parte, en un discurso radial Herrera se refirió a su "larga actuación" de "tolerancia y el olvido", disertó sobre su modestia, y pidió "disculpa por los errores que haya cometido y que son atributos de la vida pública y de su mucha complejidad", a amigos y adversarios les ofreció su "corazón generoso" en el cual no cabían ni odios ni rencores. ${ }^{36}$

Durante el año 1930, un tema que apareció en algunos discursos nacionalistas fue la propuesta de realizar una reforma constitucional. Sin embargo, en el último mes de campaña electoral solo El Nacional lo recogió como un asunto de importancia para modificar el "régimen híbrido" de presidencia y CNA, insistiendo en que fuera "libremente discutida y consentida". El medio de Quijano se desmarcaba de quienes buscaban imponerla bajo amenazas y de aquellos anticolegialistas que pretendían retroceder a "viejos presidencialismos despóticos". Las opciones eran presidencialismo, colegiado integral o régimen parlamentario. Esta última fue la bandera erigida por El Nacional, considerada como la de "esencia más democrática" y la que le quitaría al presidente "el último resto de feudalismo". El objetivo era darle más peso al poder legislativo y mayor flexibilidad a la posibilidad de finalizar un mandato ejecutivo. ${ }^{37}$ Esta mirada al presente y futuro político uruguayo se inserta en una evaluación muy negativa del contexto autoritario regional y europeo de su tiempo. Uruguay estaba "cercado" y "aislado" entre la ruptura institucional brasileña y la dictadura de José Félix de Uriburu en Argentina. En su lectura Uriburu era un símbolo del advenimiento del

\footnotetext{
34 “Lo que implicaría la derrota", El País, 9 de noviembre, 1930, 5; "Los blancos radicales no pueden decretar su eliminación en la lucha contra el coloradismo", El Nacional, 28 de noviembre, 1930, 1; Pedro Camps, "A los compañeros radicales blancos", El País, 26 de noviembre, 1930, 5.

35 "Radicales blancos", El País, 30 de noviembre, 1930, 5. En el mismo medio el 26 y el 28 de noviembre aparecieron frases en recuadros negros que manifestaban la cercanía de los radicales con el Partido Nacional y su lejanía absoluta con el Partido Colorado.

36 "Anoche el Dr. Luis A. de Herrera expuso al país su programa de gobierno", La Tribuna Popular, 7 de noviembre, 1930, 1.

37 "La reforma", El Nacional, 1 de noviembre, 1930, 1; "La reforma constitucional", El Nacional, 18 de noviembre, 1930, 1; "Más allá de la elección”, El Nacional, 22 de noviembre, 1930, 1; “Anti colegialismo y anti demagogia", El Nacional, 26 de noviembre, 1930, 1.
} 
"fascismo criollo", y una señal de alarma a que los pueblos cayeran en la creencia de los "hombres providenciales" y de los "gobiernos fuertes". El Nacional observaba que la república oriental era un "modelo" y el "último refugio de la libertad en la tierra americana" lo que revestía de actualidad a la lucha por la mejora y defensa de la democracia. ${ }^{38}$ Por ello, su línea editorial puso el foco en que solo el nacionalismo podía custodiar, consolidar y salvar la democracia política uruguaya. Esto iba unido a la necesidad de que las divisas tradicionales evolucionaran hacia una renovación con el armado de "organizaciones nuevas, de claro contenido ideológico y de marcada unidad de acción para hacer frente a nuestros problemas de la realidad nacional" para avanzar en la democracia social. ${ }^{39}$

En el ámbito de la economía, el concepto básico de las propuestas de los candidatos y políticos nacionalistas se identificaba con una visión de reducción de los impuestos y de equilibrio presupuestal, que se lograría con una administración honrada y prudente de los gobernantes. No obstante, esto no implicaba que el Estado ignorase a los sectores más desprotegidos de la sociedad, por lo que debía generar las obras de infraestructura necesarias y dinamizar la iniciativa privada. Un tema de honda preocupación era la crisis económica mundial y su repercusión local. Se advertía que enfrentar el impacto de esta amenaza requería firmeza, energía, acción y trabajo, que solo el Partido Nacional podía otorgarlas. Roberto Berro, candidato al consejo, expresaba cómo su partido buscaba la colaboración y armonía entre "los dos factores indisolubles del progreso: el capital y el trabajo". Abogaba por la intervención del Estado en la problemática social mediante una política de equilibrio entre "las absurdas pretensiones comunistas y el egoísmo retardatario de los inhumanos". ${ }^{40}$ Alfredo García Morales, también candidato al CNA, explicó que el partido no prometía puestos públicos, altos salarios ni jugosas jubilaciones que llevarían a la ruina del fisco y de la empresa privada, sino una legislación que favoreciese la iniciativa particular y la diversificación de las industrias -generando riqueza y aliviando el problema de la desocupación- desenterrando el "concepto panteísta del Estado". A la vez, respaldaba la

\footnotetext{
38 "El pueblo argentino y el dictador Uriburu", El Nacional, 4 de noviembre, 1930, 1; "Un gran ejemplo", El Nacional, 19 de noviembre, 1930, 1; "Serenidad y firmeza", El Nacional, 20 de noviembre, 1930, 1; "Consolidar la democracia", El Nacional, 25 de noviembre, 1930, 1; "La prueba", El Nacional, 5 de noviembre, $1930,1$. Caetano y Rilla, El joven Quijano, 91-94.

39 "Frente a los comicios: lo que nos une", El Nacional, 22 de noviembre, 1930, 1; "A los ciudadanos independientes", El Nacional, 26 de noviembre, 1930, 1; "A votar y vencer", El Nacional, 30 de noviembre, 1930, 1. En el caso de La Tribuna Popular amerita comentarse que las interrupciones institucionales eran condenables en Argentina, Perú y Bolivia, pero no para el caso de Brasil: "Un hermoso espectáculo", La Tribuna Popular, 30 de noviembre, 1930, 1. De hecho, celebraron que Herrera había sido uno de los "primeros hombres públicos" de Uruguay que felicitaron a Getulio Vargas. "Del Presidente de Brasil a Luis A. de Herrera", La Tribuna Popular, 8 de noviembre, 1930, 1.

40 "Hablan los candidatos del partido", El Nacional, 9 de noviembre, 1930, 1.
} 
promoción de leyes que fomentaran el cooperativismo y la protección a los más humildes para elevarlos en los ámbitos económico, ético y cultural. ${ }^{41}$ Martín C. Martínez, uno de los referentes del partido en materia económico-financiera, propuso modificar el régimen impositivo vigente, que estaba basado en los impuestos al trabajo y al consumo. Según su opinión estos debían sustituirse por un impuesto a la renta, ya que este representaría verdaderamente la capacidad económica de cada trabajador. ${ }^{42}$

Como en cada campaña nacionalista, se criticaba de forma feroz el crecimiento de los gastos del Estado y el incremento de los empleados públicos. En contrapartida el nacionalismo daba la palabra de que reduciría y racionalizaría el presupuesto, aunque sin una política de despidos. Por este motivo se ponían en la mira los riesgos de algunas iniciativas batllistas como el salario mínimo "fijo o estricto" "que dejaría en la calle por el cierre forzoso de muchos establecimientos a centenares y aún millares de obreros". ${ }^{43}$ En relación con los obreros existieron llamados concretos para atraer sus votos. En algunos discursos los presentaban como las víctimas de una política de derroches, impuestos y deudas, que llevaban a la ruina de la economía y de las industrias nacionales, con la consecuencia del aumento de la desocupación. ${ }^{44}$ En otros buscaron mostrarles que mientras ellos vivían en la inopia, sus aparentes defensores en realidad eran unos "ricachos", "millonarios" y "aristócratas" a quienes poco les interesaban sus padecimientos. ${ }^{45}$ Asimismo, los comicios eran ocasión de recordar las iniciativas que los blancos habían llevado al parlamento, y reforzar la idea de que gracias a sus conquistas podían sufragar con independencia frente al patrón y que su voto valía lo mismo que el de este. ${ }^{46}$

Es preciso señalar que la inmigración fue otra problemática abordada en su conexión con la economía. La prensa intentó desvincularse de la acusación de xenófobos y aclarar sus

\footnotetext{
41 "Ecos de la conferencia del jueves", Diario del Plata, 8 de noviembre, 1930, 3; "Fórmula electoral Herrera García Morales- Ponce de León- Estradé Gallinal”, Diario del Plata, 27 de noviembre, 1930, 3.

42 "Hablan los candidatos del Partido", El Nacional, 15 de noviembre, 1930, 1. Este artículo recoge un discurso de Otamendi, quien recomendaba crear cooperativas rurales para enfrentar a las empresas monopólicas que dominaban la exportación agropecuaria. De acuerdo con esta idea mostraba preocupación por desarrollar una política social que amparase a los débiles: mujeres, niños, viejos y trabajadores humildes.

43 "Engaña bobos", Diario del Plata, 2 de noviembre, 1930, 3. Otro tema de crítica contra el batllismo era la implementación del derecho a las jubilaciones: "Por la verdad: contra las explotaciones electoreras", Diario del Plata, 2 de noviembre, 1930, 3.

44 "Obrero, oye", La Tribuna Popular, 5 de noviembre, 1930, 1. También les pedían no olvidar que habían sido "apaleados" por la policía, consideración que se extendida a los campesinos: "A los agrarios", La Tribuna Popular, 8 de noviembre, 1930, 1.

45 "Obrero colorado", El Nacional, 5 de noviembre, 1930, 1; "Para los colorados honestos", La Tribuna Popular, 4 de noviembre, 1930, 1; "El voto de los jornaleros: algo que no se debe olvidar", El País, 27 de noviembre, $1930,5$.

46 "Ante los comicios: Los obreros y el Partido Nacional”, Diario del Plata, 23 de noviembre, 1930, 3; "Si los obreros tienen patria y derechos es por obra del Partido Nacional”, Diario del Plata, 27 de noviembre, $1930,1$.
} 
posiciones. Exigían al Estado asumir un rol "vigilante y defensivo" y que adoptase severas medidas para controlarla. Esta selección no solo debía incluir normativas ligadas a la salud, como las ya legisladas, sino también asegurar la "moralidad", "honradez", "buenas costumbres" y "hábitos de trabajo y de progreso" de los recién llegados. Además, se establecía como objetivo la atracción de inmigrantes que fuesen fácilmente asimilables a la cultura nacional, como los italianos. Así pues, según su parecer, era conveniente el rechazo de los "delincuentes de cualquier clase y quienes significan una amenaza para el orden y las instituciones nacionales", entre los que cabían desde ladrones y asesinos hasta comunistas y soviéticos. Estos últimos "disfrazan sus instintos criminales con el falso manto de ideologías avanzadas". ${ }^{47}$ Otro hecho que influía en este asunto era la crisis económica y el crecimiento de la desocupación a nivel mundial. ${ }^{48}$ Por ello, los nacionalistas resaltaban que varios países comenzaban a abandonar las políticas de "migración ultraliberales", no por motivos xenófobos sino para dar preferencia a los nacionales. En ese sentido, destacaban que se debían contemplar las medidas restrictivas de Argentina y Brasil -que podrían imitarse- y sus posibles consecuencias dañinas, como que los inmigrantes se radicasen en Montevideo en lugar de dirigirse a la campaña, lo que sería deseable para el desarrollo económico del país. En algunas notas se expresaba alarma por los migrantes procedentes de Europa oriental: "que llevan entre nosotros una vida miserable, y no siempre higiénica, van desalojando de las fábricas y de los talleres al obrero uruguayo como al obrero extranjero con vinculación, familia y larga residencia en Uruguay", 49

También se criticaba al oficialismo por el uso electoral de los extranjeros mediante la ampliación de las cartas de ciudadanía para asegurar sufragios. ${ }^{50}$ De hecho, una vez conocida la derrota en los comicios, Eduardo Rodríguez Larreta, entre otros dirigentes nacionalistas, consideró que los colorados se habían beneficiado de miles "de ciudadanos fabricados a dedo" quienes ignoraban todo lo concerniente a la realidad política local y en especial a su historia. Mientras el discurso antiinmigración llenaba varias páginas, se recordaba a los blancos

\footnotetext{
47 "La Jauja de la delincuencia internacional”, Diario del Plata, 6 de noviembre, 1930, 3; "Para los sirios y los afines", Diario del Plata, 21 de diciembre, 1930, 3; "La inmigración italiana en nuestro país", Diario del Plata, 21 de diciembre, 1930, 3.

${ }^{48}$ Son varias las notas en los distintos medios que comentaban la problemática de la desocupación a nivel mundial, por ejemplo: "15.000.000 de desocupados", El Nacional, 25 de diciembre, 1930, 1.

49 "El problema de la inmigración: ni xenofobia ni extranjerismo", Diario del Plata, 27 de diciembre, 1930, 3; "La inmigración incontrolada está agravando la desocupación", La Tribuna Popular, 21 de diciembre, 1930, 1; "Los perjuicios de la inmigración”, La Tribuna Popular, 24 de diciembre, 1930, 1; "Restricciones a la inmigración", La Tribuna Popular, 24 de diciembre, 1930, 1.

50 "El amor a los extranjeros", El País, 6 de diciembre, 1930, 5; "Ocho mil cartas de ciudadanía en dos años", La Tribuna Popular, 5 de diciembre, 1930, 1.
} 
uruguayos que se habían mudado a los países vecinos por no encontrar posibilidades de progreso en su patria, y se pedía al gobierno dar facilidades para que pudieran regresar a votar. $^{51}$

Los nacionalistas apelaban al conjunto de la ciudadanía para sumarse a su proyecto político, particularmente a los católicos. En esta oportunidad, la Unión Cívica, partido católico, no presentó candidatos para la presidencia ni para consejeros, al tiempo que recomendó no votar por listas coloradas. ${ }^{52}$ Los nacionalistas si bien aclaraban que no eran una colectividad católica, recordaban que sus actos siempre habían estado guiados por la tolerancia y el respeto hacia la religión y las conciencias. También al ser un partido "verdaderamente liberal" era una garantía de que nunca se utilizarían medios de coacción para impedir expresar ideas religiosas y que su prédica, "serena y razonada", no caería en el insulto y el escarnio de los creyentes. ${ }^{53}$ En paralelo, se recordaba la "fobia anticatólica" del batllismo y los riegos de su triunfo. ${ }^{54} \mathrm{Al}$ mismo tiempo, pedía a las clases conservadoras votar al nacionalismo porque resguardaría el derecho a la herencia, a diferencia del batllismo que pretendía erradicarlo. ${ }^{55}$

Por último, cabe remarcar que en los meses precedentes a la elección de noviembre se constituyeron, como era tradicional en estas circunstancias comiciales, diversos comités partidarios que tenían como finalidad realizar propaganda por los candidatos. En particular, se percibe una consolidación del vínculo entre Herrera y sus seguidores: quienes apoyaban su candidatura lo llamaban Jefe Civil y se autodefinían como herreristas, demostrando así el incremento de su influencia como personalidad y líder en su círculo de votantes. Asimismo, un gran número de comités solicitaban la presencia de Herrera en sus conferencias y actos partidarios de cara a las elecciones como un elemento indispensable para atraer votantes y consolidar sus bases. ${ }^{56}$

\footnotetext{
51 "La persecución de los hombres nacidos en este país", El País, 3 de noviembre, 1930, 5; "La gran mistificación de los gatos internacionales", El País, 18 de noviembre, 1930, 5. En este último artículo se planteó que no se podía "recibir las resacas de las sociedades extranjeras que llegan a convulsionar la tranquila, liberal, hospitalaria sociedad uruguaya".

52 "Los católicos no deben votar listas coloradas: lo dicen autoridades de su partido", Diario del Plata, 23 de noviembre, 1930, 3 .

53 "Cómo deberán votar los católicos", Diario del Plata, 9 de noviembre, 1930, 3; “A votar! (sic.)", La Tribuna Popular, 26 de noviembre, 1930, 1

54 "Fuimos dique al sectarismo", El País, 28 de noviembre, 1930, 5; "Lo que se dice: para los católicos y los indiferentes", La Tribuna Popular, 28 de noviembre, 1930, 8; "No estamos conformes con el Partido Nacional", El País, 26 de noviembre, 1930, 5; "El deber es votar el Partido Nacional", Diario del Plata, 28 de noviembre, $1930,1$.

${ }^{55}$ Sobre la amenaza a la herencia por parte del batllismo son incontables las notas, por ejemplo: "No pueden olvidarlo", El País, 29 de noviembre, 1930, 5.

${ }^{56}$ Museo Histórico Nacional (Uruguay), Archivo Luis Alberto de Herrera, carpetas 3652 y 3653.
} 


\section{Después de la derrota}

La admisión del fracaso electoral se reconoció prácticamente al día siguiente de los comicios, puesto que el crecimiento del Partido Colorado en Montevideo fue un dato irrefutable que no podría ser compensado por los votos de la campaña que aún faltaban procesar. ${ }^{57}$ En cuanto al significado de la jornada electoral Diario del Plata destacó su "ejemplo de civismo y de virtud republicana", y acrecentó su valor en un contexto en el que países más ricos se "muestran ineptos para la vida democrática e inadaptables a la libertad". En esta dinámica, descartaba la posibilidad de un fraude organizado, y sostenía que las escasas acusaciones de coacción policial para votar no parecían responder a una directiva oficialista. ${ }^{58}$ Sin embargo, unos días más tarde tanto El País como La Tribuna Popular comenzarían una ardua campaña bajo la bandera de la "pureza del sufragio" y de la "moral política" para presionar por la anulación de las elecciones en Montevideo a raíz del descubrimiento de hechos fraudulentos en comisarías, cuarteles y oficinas públicas. ${ }^{59}$

Las explicaciones sobre la victoria colorada fueron múltiples. Los principales argumentos desplegados fueron el uso de los recursos del Estado para comprar solidaridades y recompensar adhesiones de empleados públicos y obreros. Herrera remarcó que su actitud como consejero había sido la opuesta y que en ese cargo había denunciado que trabajadores de un ente autónomo lo habían amenazado con que no lo votarían sino aumentaba sus sueldos. También fue objeto de crítica la gran velocidad de la nacionalización de extranjeros, quienes se habían convertido en colorados por haber encontrado trabajo rápidamente en el país. Otra de las ventajas del Partido Colorado era la convivencia en su lema de una candidatura conservadora y otra "incendiaria" que atraía a las izquierdas, al tiempo que el apoyo de algunos votantes al hándicap les restó votos en sectores conservadores. ${ }^{60}$

\footnotetext{
57 "Los resultados conocidos son pesimistas", El País, 1 de diciembre, 1930, 1.

58 "Después de la jornada", Diario del Plata, 1 de diciembre, 1930, 1. En el mismo sentido se expresó El Nacional recalcando el orden, el respeto y la tranquilidad, y su confianza en la democracia "en esta hora de barbarie de reacción". "Cultura cívica", El Nacional, 1 de diciembre, 1930, 1; "Lo que hemos conquistado firmemente", El Nacional, 3 de diciembre, 1930, 1.

59 "Gracias a un escandaloso fraude el batllismo triunfó en Montevideo", La Tribuna Popular, 8 de diciembre, 1930, 1; "La gran estafa electoral oficialista plenamente descubierta", La Tribuna Popular, 9 de diciembre, 1930, 1; "Poco a poco se van comprobando los fraudes electorales", La Tribuna Popular, 10 de diciembre, 1930, 1; "Hay que organizar la oposición”, La Tribuna Popular, 12 de diciembre, 1930, 1; "La gran estafa electoral", La Tribuna Popular, 14 de diciembre, 1930, 1. El directorio del partido se pronunció de forma categórica, véase: El País, 8 de diciembre, 3.

60 "Ante el hecho consumado", Diario del Plata, 2 de diciembre, 1930, 3; "Al margen de los comicios: el electoralismo y su influencia", Diario del Plata, 4 de diciembre, 1930, 3; "Resonancia de los comicios", Diario del Plata, 3 de diciembre, 1930, 3; "No tengo empleos que dar", La Tribuna Popular, 5 de diciembre, 1930, 1; “Para sacar en limpio”, La Tribuna Popular, 3 de diciembre, 1930, 1; “¿Quién triunfó?”, El País, 6 de diciembre,
} 
Como contrapartida, Diario del Plata evaluaba que la prédica y el accionar de los políticos nacionalistas no eran atractivas electoralmente, como la frase de Herrera "no tengo empleos que dar", el hecho de que sus consejeros no habían aprobado ampliar los gastos de varios entes públicos y que sus legisladores se opusieron a la creación de un salario mínimo uniforme. De tal modo, el problema no sería la propuesta nacionalista de control presupuestal, sino la incapacidad del ciudadano de comprender que los gastos excesivos comprometían "la bancarrota del erario y la ruina de la economía nacional". ${ }^{61}$ El análisis de la derrota consideraba que, si bien su desempeño había sufrido un revés tampoco era tan grave, ya que se habían pasado épocas peores. Según su postura, era positivo contar con más de 150.000 votantes, mayoría en el Senado, un número significativo de diputados y doce de los diecinueve departamentos. Además, se minimizó la pérdida de un consejero en el CNA porque incluso si hubieran ganado continuarían siendo minoría. Debido a lo anterior, Diario del Plata exigió serenidad y "estrechar las filas", puesto que no era momento de deprimirse y buscar culpables, entre los que estarían Herrera, por haber fracasado tres veces en su intento de llegar a presidente, y en segundo lugar el directorio. Esta actitud no era recomendable porque podría dividir y debilitar la cohesión partidaria. Aunque el medio de Juan Andrés Ramírez no era un ferviente partidario de Herrera, le reconocía sus méritos y su número de seguidores. En cuanto al directorio manifestaba que era peligroso condenarlo como "cabeza de turco" porque estaba integrado por miembros que representaban a los distintos matices de la colectividad. ${ }^{62}$ En sintonía, El País salió en defensa del directorio y declaraba que no era una coyuntura propicia para recriminaciones y peleas. ${ }^{63}$

La posición de Diario del Plata para explicar la derrota electoral contrasta con la actitud virulenta de La Tribuna Popular, que encontró en las autoridades partidarias, excluyendo al grupo herrerista en su seno, el chivo expiatorio que debía ser erradicado, por lo que planteó abiertamente la renovación directiva y de orientación ideológica, pidiendo más peso de los dirigentes populares frente a los conservadores. El $1^{\circ}$ de diciembre, en una nota de portada cargada de drama y pesimismo, anunció que "días sombríos se avecinan”, y hacía un

1930, 5. El Nacional reprodujo declaraciones de varios dirigentes nacionalistas que se pronunciaron sobre la victoria colorada: "El oficialismo ha decidido la elección", El Nacional, 2 de diciembre, 1930, 1; "La derrota del Partido", El Nacional, 5 de diciembre, 1930, 1; "Las causas de la derrota”, El Nacional, 3 de diciembre, 1930, 1; "El Partido Nacional reaccionará plenamente", El Nacional, 2 de diciembre, 1930, 1.

61 "Ante la gravedad del momento", Diario del Plata, 5 de diciembre, 1930, 3.

62 "A un mes de la elección", Diario del Plata, 30 de diciembre, 1930, 3; "El deber del momento", Diario del Plata, 6 de diciembre, 1930, 3.

63 "No es soplar y hacer botellas", El País, 8 de diciembre, 1930, 5; "La responsabilidad del directorio: ¿Había acaso 'ceros a la izquierda' en esa autoridad?", El País, 4 de diciembre, 1930, 5; "El directorio renunciante”, El País, 3 de diciembre, 1930, 5; “A la revancha: no llantos ni peleas”, El País, 3 de diciembre, 1930, 5. 
difuso llamado a "salvar a la patria". Desde su mirada, el principal culpable era el pueblo, de cuyo "error funesto" sería la principal víctima. Es decir, el pueblo eligió perpetuar la demagogia, a los "embusteros de oficio", al "ejército burocrático" y a la acción de la "máquina de tortura" del batllismo que "amenaza a la democracia en sus fundamentos de orden, de honestidad y de justicia”. En su lógica, ese pueblo perdía derechos, como el de protestar por los excesivos impuestos y por la difícil situación económica del país. ${ }^{64}$ Sus páginas se hicieron eco de declaraciones exclusivas de Luis Alberto de Herrera, cuyo lenguaje muestra mimetismo con el de este medio periodístico, ya que primero criticó con crudeza el fraude de policía y tropas, deploró a los ciudadanos "egoístas" que "no respondieron al mandato del patriotismo", por lo que no era momento de "llorar ahora como mujeres lo que no supieron defender como hombres" y sentenció que "nada más cierto que aquello de que cada país tiene el gobierno que se merece". ${ }^{65}$ Cabe consignar que existía una tensión discursiva entre el pueblo culpable y el pueblo víctima de la hegemonía batllista resucitada de la "urna funeraria del Partido Colorado". ${ }^{66}$ La idea del pueblo víctima se expuso con varias imágenes simbólicas que ponían de manifiesto el dramatismo de un "país muerto" en el "campo de batalla", o la de un pueblo en "duelo nacional". ${ }^{67}$

Más allá de la culpabilidad del oficialismo, La Tribuna Popular consideraba que la elección del 30 de noviembre era ocasión para reflexionar sobre "la verdad" de la derrota, "sin eufemismos". En otras palabras, hubo incompetencia en las propias filas partidarias, desde los indiferentes que no fueron a votar hasta la falta de movilización de los "caudillos de barrio". En especial, acusó al electorado montevideano de haber "traicionado la gloriosa tradición del Partido". ${ }^{6}$ Hilando más fino en la búsqueda de responsabilidades se exponían dos desperfectos: el de la organización partidaria y el de la indefinición ideológica. En cuanto al primero afirmaban que eran las autoridades de la capital las que plantaron la semilla de la derrota con la ausencia de un plan, por lo que exigían su recambio. Entre estas fallas

\footnotetext{
64 “Desfavorables para la democracia fueron los comicios de ayer", La Tribuna Popular, 1 de diciembre, 1930, 1; “¿Nos cruzaremos de brazos?”, La Tribuna Popular, 7 de diciembre, 1930, 1. También puede complementarse: "A rehacerse y luchar", La Tribuna Popular, 7 de diciembre, 1930, 1; "Aumentará la burocracia", La Tribuna Popular, 1 de diciembre, 1930, 1; "Los discursos políticos", La Tribuna Popular, 2 de diciembre, 1930, 1; "Enfermos de indolencia", La Tribuna Popular, 1 de diciembre, 1930, 1. En este último se declara con "dolor" que "nuestro partido es una agrupación nacida para ser vencida".

65 “El Dr. Luis Alberto de Herrera habla para La Tribuna Popular", La Tribuna Popular, 4 de diciembre, 1930, 1.

66 "Resurrección de la oligarquía batllista", La Tribuna Popular, 2 de diciembre, 1930, 1.

67 "Proporciones de la derrota del 30", La Tribuna Popular, 3 de diciembre, 1930, 1.

68 "Un puñado de verdades", La Tribuna Popular, 1 de diciembre, 1930, 1. No obstante, se reconoció la heroicidad del votante de campaña que cumplió su deber a pesar de las lluvias, los desbordes de los ríos y el barro de los caminos. "Hay que organizar la oposición", La Tribuna Popular, 12 de diciembre, 1930, 1. De esta manera, el diario reactualizaba la dicotomía campo-ciudad, contrastando las virtudes del primero frente a una falta de compromiso de la segunda.
} 
organizativas se incluyó la ausencia de delegados, o su participación sin conocimiento de su labor en las mesas, la falta de listas en los cuartos de votación y una incomprensión de que para ganar una campaña se requería gastar más dinero. ${ }^{69}$ De cara al futuro, se recomendaba aprender del modelo organizativo de la Unión Cívica Radical argentina por su eficiencia técnica, disciplina férrea y actividad incansable: "en cada cuadra existía un ciudadano radical que llevaba un registro de los correligionarios domiciliados en esa cuadra y sobre los que ejercía continúa acción propagandista". Por el contrario, señalaba que en el nacionalismo había un total desconocimiento de los domicilios de sus adherentes. ${ }^{70}$

En cuanto al problema ideológico manifestaba que el partido estaba quebrado por un "avancismo casi revolucionario" frente a un "conservadurismo ultramontano". Entre estos dos polos las masas no encontraban claridad de guía, aunque sí reconocía que el "tradicionalismo" que antes las movían "es cada vez una fuerza más débil”, por lo que era necesario adaptarse "al diapasón de los tiempos". ${ }^{71}$ Los argumentos apuntaron a una solicitud abierta de reemplazo del directorio por incapaz, exceptuando a unos pocos de sus miembros, y por haber librado una "guerra de boutique" o un "vergonzoso motín interno" contra "el jefe indiscutido del nacionalismo, doctor Luis Alberto de Herrera". ${ }^{72}$ Los ánimos estaban tensos y se sucedieron varios incidentes en la sede del partido, donde varios nacionalistas pedían a "gritos" la renuncia del directorio. Para calmar el descontento Leonel Aguirre, presidente del directorio, anunció una dimisión colectiva que se ejecutaría cuando finalizara el escrutinio definitivo. ${ }^{73}$ A fines de diciembre, Herrera renunció al directorio, y arrastró a otros miembros, pidiendo a los restantes cumplir con su promesa. ${ }^{74}$ Finalmente, en enero de 1931, se efectuó el recambio del directorio y se desplazó a los dirigentes más afines con Herrera. ${ }^{75}$

Por su parte, El Nacional partió de la base de que los reveses formaban parte del “juego de las democracias” y que servían para la renovación y la reorganización partidaria, dos conceptos fundamentales que caracterizaron su prédica postelectoral. Esta actitud carente

\footnotetext{
69 "Las lecciones de la experiencia", La Tribuna Popular, 2 de diciembre, 1930, 1; "Comentando la derrota", La Tribuna Popular, 2 de diciembre, 1930, 1.

70 "Lo que debió hacerse", La Tribuna Popular, 3 de diciembre, 1930, 1. También consideraban que debían incorporarse más jóvenes en la dirección partidaria: "El nuevo directorio nacionalista", La Tribuna Popular, 5 de diciembre, 1930, 1.

71 "Las lecciones de la experiencia", La Tribuna Popular, 2 de diciembre, 1930, 1; "Comentando la derrota", La Tribuna Popular, 2 de diciembre, 1930, 1.

72 "Comentando la derrota", La Tribuna Popular, 2 de diciembre, 1930, 1; "En la hora de la serenidad", La Tribuna Popular, 2 de diciembre, 1930, 1.

73 "Renunciará el directorio nacionalista", La Tribuna Popular, 3 de diciembre, 1930, 1; "La Agrupación Nacional Saravista ratifica su pedido de renuncia del Directorio", La Tribuna Popular, 4 de diciembre, 1930, 1; "Tumulto frente al Club Nacional", El Nacional, 3 de diciembre, 1930, 1.

74 "Renunció el Dr. Herrera", La Tribuna Popular, 31 de diciembre, 1930, 2.

${ }^{75}$ Caetano y Jacob, El nacimiento del terrismo, 189-191.
} 
de pesimismo no implicaba desconocer y minimizar la angustia del "pueblo nacionalista" 76 Tampoco era buen consejero, desmarcándose de varios correligionarios, montar un "juicio de responsabilidad contra algunos hombres dirigentes", porque no era momento de arrastrarse por las pasiones, la deslealtad y la injusticia. Desde su perspectiva el problema no eran los hombres, sino una cuestión de "estructura partidaria, de táctica y de fines políticos". El Partido Nacional se había mantenido unido ideológicamente mientras su meta fundamental había estado puesta en la "creación de la democracia política", pero desde hacía años los problemas económicos y sociales requerían una mejora, y en su respuesta faltó una definición ideológica unificadora. ${ }^{77}$ Desde su punto de vista, en el nacionalismo primaban dos concepciones en materia económica y social, una conservadora y otra más avanzada, que no habían podido arribar a posiciones intermedias:

"Hay quienes en el Partido Nacional, son individualistas, defensores de la organización presente, partidarios de un régimen de libre concurrencia y de salvaguardia de lo que se llama actividad privada. Y están los otros, los partidarios del intervencionismo del Estado, que creen injusto y perjudicial el sistema que nos rige, desconfían de la llamada libertad económica y pueden llegar hasta creer, que no sólo razones de justicia, sino también de defensa del país exigen que determinadas actividades, para escapar al posible contralor de los capitalismos imperialistas, sean nacionalizados, que no es lo mismo que monopolizadas, de acuerdo con la vieja fórmula, por el Estado", 78

Así pues, según su línea argumentativa el Partido tendría dos posibilidades: procurar un ideal unitario o permitir la diversidad en su seno, y de no prosperar ninguna de esas opciones, el nacionalismo acabaría dividido de forma irreconciliable. El Nacional se inclinaba por la segunda opción, manteniendo la unidad partidaria solo en relación con la "custodia de la democracia política". Esta vía significaría una reforma de los estatutos partidarios y dejar libertad de acción a cada tendencia dentro del parlamento, es decir, desenterraría la práctica

\footnotetext{
76 “Confiar en el porvenir", El Nacional, 2 de diciembre, 1930, 1; "El pueblo nacionalista", El Nacional, 2 de diciembre, 1930, 1.

77 "Renovarse es vivir", El Nacional, 2 de diciembre, 1930, 1. Dos días más tarde, el medio, desvinculándose de las críticas que se hacían a su lectura de la derrota aclaró nuevamente que su deseo no era provocar polémica dentro de filas, lo que de hecho era un riesgo porque el principal perjudicado sería el partido, e insistió: "vamos a guardar todos la serenidad y a no empezar a tirarnos los trastos por la cabeza". "Para calmar a los nerviosos", $E l$ Nacional, 4 de diciembre, 1930, 1.

78 "Hacia adelante", El Nacional, 4 de diciembre, 1930, 1. Otro artículo que reflexiona sobre este tema: "Avanzados y conservadores", El Nacional, 7 de diciembre, 1930, 1; "Nacionalizaciones", El Nacional, 9 de diciembre, 1930, 1. En el grupo "avanzado" se situaba la línea editorial del periódico de defensa del capital nacional frente al imperialismo, sin promover un aislamiento económico "insensato" en un marco de interdependencia de la economía mundial.
} 
del voto en bloque que siempre había sido favorable a los conservadores. Desde este diario remarcaban que esta opción no implicaría eliminar los valores tradicionales del partido, debido a que "Evolucionar no es ruptura con el pasado; es continuidad". 79

Por todo ello, para este medio la elección de 1930 era ocasión de reflexionar sobre cómo afianzar la democracia y abordar la crisis de los partidos tradicionales uruguayos. Según su enfoque, el Partido Nacional no podía acabar como el colorado, completamente fraccionado y solo funcionando como un acuerdo electoral, ya que eso no era sano para la democracia porque llevaría a la política por el camino de la personalización y la demagogia. Más allá de su pedido de renovación y reorganización intra partidaria, se ponía en cuestión la constitución de 1917, considerando que la coparticipación había perjudicado al partido: "No fuimos fuerza suficiente para imponer normas ni fuerza lo bastante débil como para poder convertirnos en oposición decidida y franca. El pacto nos dio parte del poder, lo bastante para comprometernos, demasiado poco para actuar". ${ }^{80}$ En consecuencia, su solución estribaba en la reforma constitucional camino a un régimen parlamentario sin colegiado, propuesta que había signado su campaña electoral, puesto que permitiría "la colaboración transitoria de fuerzas que $(. .$.$) frente a problemas concretos pudieran acordar soluciones comunes". { }^{81}$

En relación con este tema, La Tribuna Popular inició una intensa campaña a favor de la "urgencia de la reforma constitucional", y discrepó de los dirigentes partidarios vinculados al diario El País, para quienes el asunto requería esperar. La visión de La Tribuna Popular era que el "sentimiento" del pueblo nacionalista era "abiertamente anticolegialista", lo que obligaba a la acción. ${ }^{82}$ Su discurso era lapidario hacia el colegiado y el batllismo, ilustrado como una "máquina de disolución del carácter nacional" y "lápida, sobre la República". Anunció con letras en mayúsculas que "El Partido Nacional ha pasado a la oposición; a la oposición tendido en batalla". Denunció a quienes no advertían la gravedad que se avecinaba

\footnotetext{
79 "Insistiendo", El Nacional, 5 de diciembre, 1930, 1; "La reorganización partidaria", El Nacional, 11 y 12 de diciembre, 1930, 1. "Cuentas claras", El Nacional, 16 de diciembre, 1930, 1. También se pedía mejorar el funcionamiento democrático en el seno del partido: "Organización partidaria", El Nacional, 15 de diciembre, 1930, 1. El País, autodefinido como la tendencia "anti demagógica", planteó la necesidad de reorganizarse frente a la velocidad que estaban imprimiendo los "avanzados". "Avanzados y conservadores dentro del Partido Nacional", El País, 5 de diciembre, 1930, 5.

80 "Renovarse es vivir", El Nacional, 2 de diciembre, 1930, 1.

81 "Insistiendo", El Nacional, 5 de diciembre, 1930, 1. En la misma línea: "Régimen parlamentario y evolución politida (sic.)", El Nacional, 3 de diciembre, 1930, 1.

82 "Hay urgencia en reformar la constitución", La Tribuna Popular, 29 de diciembre, 1930, 1. Unos días antes, Herrera declaró que el auténtico sentimiento nacionalista estaba contra el colegiado: "Categóricas declaraciones del doctor Luis A. de Herrera", La Tribuna Popular, 16 de diciembre, 1930, 1. El País alertó de los riesgos de efectuar comicios anualmente y de la injusticia de la ley de lemas: "La frecuencia de las elecciones", El País, 11 de diciembre, 1930, 5 y "Los abusos del doble voto simultáneo", El País, 10 de diciembre, 1930, 5. No obstante, en sus páginas no se trasmitía, como en La Tribuna Popular, transitar a un cambio constitucional.
} 
en el país, y según su postura era preocupante que parte de esos "espíritus" militaban en el nacionalismo, a quienes los invitaba de forma categórica a marcharse "cuanto antes" porque sobraban, incomodaban y no servían. ${ }^{83}$

\section{Conclusiones}

El Partido Nacional se concebía a sí mismo como el abanderado de la verdadera tradición democrática, que traería estabilidad, respeto institucional, un gobierno de unidad nacional y honradez administrativa para iniciar una época próspera y feliz. Bajo estas promesas y creencias la campaña electoral nacionalista de 1930 tuvo sus trazos de continuidad con sus banderas identitarias caracterizadas por la defensa del liberalismo político y económico, el que contemplaba el desarrollo de una moderada y prudente legislación social que protegiera a los más humildes y no se enemistara con el capital ni con la iniciativa privada. Esta identidad cobraba fuerza en su binario contraste con lo que desde su perspectiva representaban los colorados, identificados como corruptos, inmorales, dictatoriales y que eran capaces de tergiversar la democracia con acuerdos electorales como el hándicap, particularmente vilipendiado por los nacionalistas.

El Partido Nacional buscó atraer y cooptar el voto de la sociedad como un conjunto, ya que en su lógica era el único representante válido de la voz del pueblo. En particular, se apeló a los obreros, católicos y clases productivas, señalando que solo un gobierno auténticamente liberal respetaría a la religión y permitiría el desenvolvimiento económico de sus ciudadanos gracias a la reducción de las cargas impositivas. Es importante consignar que la Agrupación Demócrata Social liderada por Carlos Quijano supuso una singularidad dentro del nacionalismo, ya que obligó a poner sobre la mesa de discusión la necesidad de precisar las distintas tendencias ideológicas, donde ellos traían la novedad en materia económica y social, un debe, desde su visión, en la historia nacionalista. Especialmente, su propuesta de reforma constitucional basada en el parlamentarismo, considerada como una fórmula que revalorizaría y extendería la democracia a través del Poder Legislativo que controlara al Poder Ejecutivo y evitara así los posibles abusos de poder de un presidente que aspirara a excederse en sus funciones.

\footnotetext{
83 "Hay que destruir la máquina que elabora la disolución del carácter nacional”, La Tribuna Popular, 26 de diciembre, 1930, 1. En este artículo se usa una metáfora médica para ilustrar cómo después de los comicios de 1930 el colegiado, una verruga inofensiva, se transformó en un cáncer maligno. También justifica que el Partido Nacional nunca había sido colegialista, y que solo lo aceptó en la constitución de 1917 por no quedarle alternativa.
} 
A pesar de la concordia y los llamados para que todos, hasta los blancos radicales, votaran dentro de la agrupación, el Partido Nacional no pudo lograr su ansiado objetivo de ganar las elecciones. Finalmente, la victoria del colorado Gabriel Terra hundió a las filas nacionalistas en el desánimo y pesimismo, desarrollándose intensas discusiones que en el transcurso de los meses sellarían la división del partido. Un partido que en la última década se había vanagloriado de su unidad, armonía y pacífica convivencia. Por otra parte, la derrota intensificó el peso de las voces que bregaban sobre la necesidad de la reforma de la constitución, con diferentes propuestas para acabar con el ejecutivo bicéfalo que era símbolo de la coparticipación entre las divisas tradicionales y que, en definitiva, desde la lectura nacionalista, había perjudicado al partido más que beneficiado.

En esa ruptura interna la figura de Luis Alberto de Herrera fue altamente controvertida. Mientras que un gran grupo de correligionarios lo veía como el líder indiscutido del partido y quien recogía las aspiraciones populares, otros lo culparon de la derrota y se preocupaban cada vez más en resaltar su personalismo y demagogia. Así pues, a raíz de esta elección cobraron mayor visibilidad las disputas entre herreristas y antiherreristas, que en el año 1931 adquirirían particular virulencia, y consumarían la división del partido durante casi tres décadas. Por tal motivo, esta campaña electoral se constituyó como un parteaguas existencial en la vida e historia del Partido Nacional. 